Check for updates

Cite this: RSC Adv., 2018, 8, 32909

Received 5th August 2018

Accepted 17th September 2018

DOI: $10.1039 / \mathrm{c} 8 \mathrm{ra06588h}$

rsc.li/rsc-advances

\section{Selective and sensitive spectrofluorimetric quantification of velpatasvir in presence of sofosbuvir. Application to their co-formulated tablet}

\author{
Rania M. El-Gamal, $\uparrow^{\star a b}$ Sherif A. Abdel-Gawad, $\uparrow^{\mathrm{ac}}$ Fathalla F. Belal $\dagger^{\mathrm{b}}$ \\ and Moustapha E. Moustapha ${ }^{d}$
}

A new sensitive, rapid and simple spectrofluorimetric method was utilized for the assessment of velpatasvir (VPS) in its bulk form as well as in its combined tablet with sofosbovir (SFV). The technique relies on measuring the native fluorescence of VPS in methanol at $385 \mathrm{~nm}$ and $400 \mathrm{~nm}$ after excitation at $295 \mathrm{~nm}$. The fluorescence-concentration plots were rectilinear through the range of $2.0-20.0 \mathrm{ng} \mathrm{mL}^{-1}$ at both emission maxima with lower detection limits of $0.146 \mathrm{ng} \mathrm{mL} \mathrm{m}^{-1}$ and $0.378 \mathrm{ng} \mathrm{mL}$, and lower quantification limits of $0.444 \mathrm{ng} \mathrm{mL}^{-1}$ and $1.147 \mathrm{ng} \mathrm{mL}^{-1}$ at $385 \mathrm{~nm}$ and $400 \mathrm{~nm}$, respectively. The proposed method was appropriately used for the analysis of VPS in its commercial tablet formulation and the results were in good agreement with those achieved with the applied comparison method.

\section{Introduction}

Hepatitis $\mathrm{C}$ virus (HCV) infection can be considered as a dangerous disease, affecting about three to five million people in the United States (US) and about one hundred and seventy million people worldwide. This disease has no symptoms in the early stages but if it becomes chronic, it may lead to dangerous life-threatening complications, including liver failure, hepatocellular carcinoma and death. ${ }^{1}$ Velpatasvir (VPS $)$ is methyl $\{(2 S)-1-[(2 S, 5 S)-2-(9-\{2-[(2 S, 4 S)-1-\{(2 R)-2-$ [(methoxycarbonyl)amino]-2-phenylacetyl $\}-4-($ methoxymethyl) pyrrolidin-2-yl]-1H-imidazol-4-yl\}-1,11-dihydro[2]benzopyrano $\left[4^{\prime}, 3^{\prime}: 6,7\right]$ naphtho[1,2- $\left.d\right]$ imidazol-2-yl)-5-methylpyrrolidin-1-yl]3-methyl-1-oxobutan-2-yl\}carbamate, Fig. 1.

It is a Direct-Acting Antiviral (DAA) drug that can be used in combination with sofosbuvir (SFV) for HCV treatment. It acts as a defective substrate for NS5A and so it plays an important role in preventing viral replication. ${ }^{2} \mathrm{SFV}$ is a nucleotide analog NS5B polymerase inhibitor. It is a prodrug which can be utilized for

${ }^{a}$ Pharmaceutical Chemistry Department, College of Pharmacy, Prince Sattam Bin-Abdul Aziz University, P. O. Box 173, Al-Kharj, 11942, Kingdom of Saudi Arabia. E-mail: r_m_elgamal@yahoo.com; Fax: +966 115886832; Tel: +966 561411680

${ }^{b}$ Department of Pharmaceutical Analytical Chemistry, Faculty of Pharmacy, Mansoura University, Mansoura, Egypt

'Analytical Chemistry Department, Faculty of Pharmacy, Cairo University, Cairo, ET11562, Egypt

${ }^{d}$ Department of Chemistry, College of Science and Humanities, Prince Sattam BinAbdul Aziz University, Al-Kharj, 11942, Kingdom of Saudi Arabia

$\dagger$ Current address: College of Pharmacy, Prince Sattam Bin-Abdul Aziz University, King Abdullah Road, Al-Kharj, Kingdom of Saudi Arabia.
HCV treatment, either alone or in combination with other drugs like, ribavirin, ledipasvir and VPS. ${ }^{3}$ In June 2016, The FDA (Food and Drug Administration) approved a fixed dose combination of SFV and VPS for the treatment of adult patients with chronic HCV infection (genotypes 1, 2, 3, 4, 5, or 6). ${ }^{4}$ Referring to the literature, SFV alone was determined using chromatographic and spectrophotometric techniques. ${ }^{5,6}$ Also, SFV forced degradation was investigated using liquid chromatography-tandem mass spectrometry (LC-MS/MS). ${ }^{7}$ On the other hand, simultaneous determination of SFV and VPS was performed using different RP-HPLC methods. ${ }^{8-11}$

A single spectroflurimetric method had been recently reported for the assay of VPS in pharmaceutical tablets and body fluids. ${ }^{12}$ The developed method was based on dispersive solid phase extraction (dSPE) utilizing the synergistic effect of reduced graphene oxide (RGO) and cobalt hydroxide nanoparticles (CHNPs) in addition to cloud point extraction (CPE) using polyethylene glycol 6000 (PEG 6000) as non-ionic surfactant. Despite the sensitivity of the method it is highly complicated with time consuming procedures that outweighs its merits.

The goal of this work was to adopt a novel simple, rapid, sensitive and economic spectroflurimetric method for the selective quantification of VPS in presence of SFV either in bulk or dosage forms.

\section{Experimental}

\subsection{Apparatus}

A spectrofluorophotometer with a xenon lamp, model FP-8200 JASCO; Japan was utilized. A quartz cell of $1 \mathrm{~cm}$ path length 


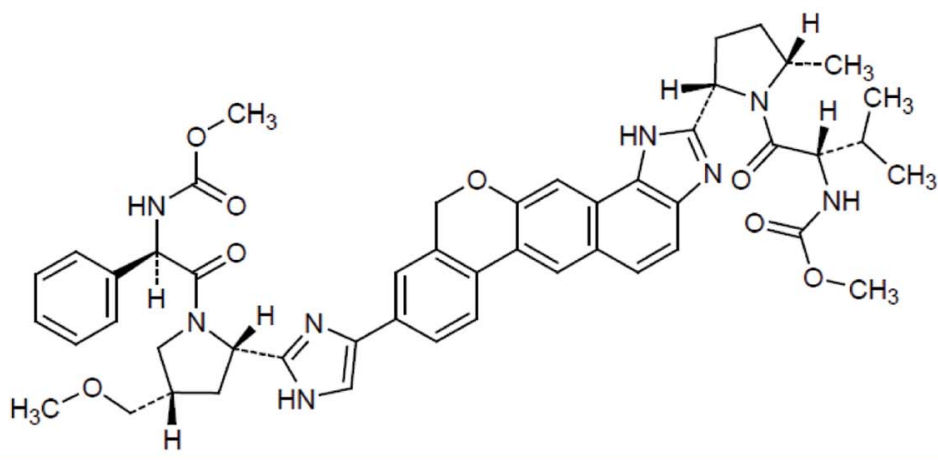

Fig. 1 The structural formulae of VPS.

was used for all measurements. The slit widths were $10 \mathrm{~nm}$ for both excitation and emission, the sensitivity was adjusted at low sensitivity. pH measurements were determined using a Consort NV P-901 pH meter (Belgium). An ultrasonic bath, model Branson 2800 was utilized as well. A\&D GR300 analytical balance.

\subsection{Materials and reagents}

All chemicals utilized in this work were of analytical grade and the solvents were of HPLC grade. Deionized water was used for all preparations.

- VPS (Catakog \#B1194-5, 25 and Lot \#2L30B11940) was purchased from BioVision, Milpitas Boulevard, Milpitas, CA 95035 USA. Its purity percentage was certified to be $\geq 98 \%$.

- SFV (PSI-7977) was purchased from Cayman chemical company, Ann Arbor, USA. Its purity percentage was $99.98 \pm$ 0.741 . $^{8}$

- Sodium dodecyl sulphate (SDS) and sodium acetate trihydrate, were purchased from Lobachemie, Mumbai, India.
- Methanol, acetonitrile, acetone and n-propanol were obtained from Sigma-Aldrich (Germany).

- Glacial acetic acid was obtained from BDH laboratory supplies, England.

- Sodium hydroxide pellets and boric acid were obtained from central drug house $(\mathrm{CDH})$, New Delhi, India.

- Tween-80, methyl cellulose, borax were all obtained from Assagaf pharma, Saudi Arabia - acetate buffer $\left(0.2 \mathrm{~mol} \mathrm{~L}^{-1}\right)$ solution was used. It was of $\mathrm{pH}$ range 3.0-5.5. Borate buffer (0.2 $\left.\mathrm{mol} \mathrm{L}^{-1}\right)$ solution was used. It was of $\mathrm{pH}$ range 6.0-8.7. Aqueous solutions $(1.0 \% \mathrm{w} / \mathrm{v})$ of Tween-80, methylcellulose and SDS were prepared and used.

\subsection{Dosage form}

Epclusa ${ }^{\circledR}$ extended-release tablets (NDC 51267-890-99) labeled to contain $400 \mathrm{mg}$ SFV and $100 \mathrm{mg}$ VPS per tablet. It was manufactured by Gilead Sciences International, Cambridge, UK.

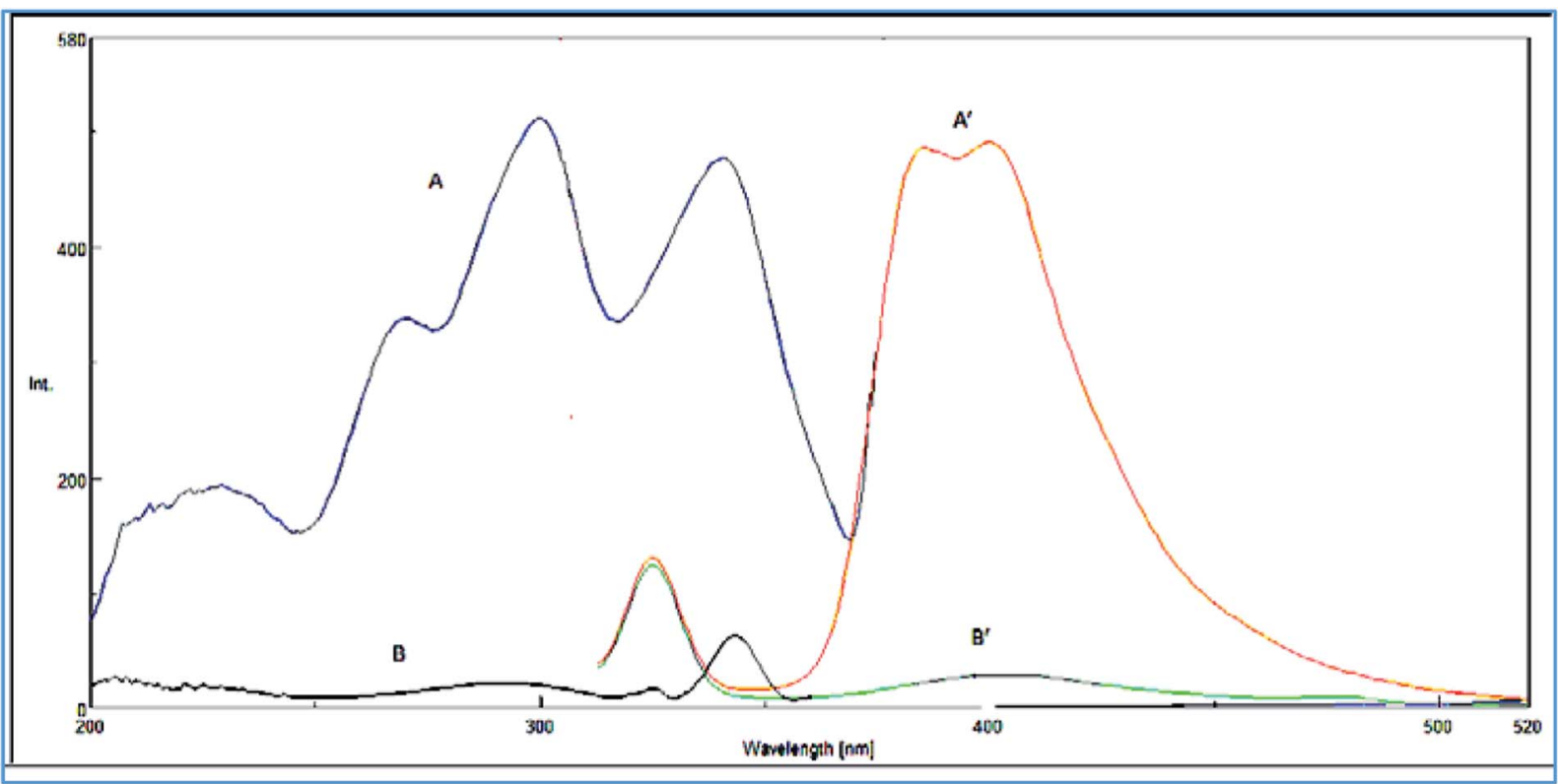

Fig. 2 (A) Excitation and ( $\left.\mathrm{A}^{\prime}\right)$ emission spectra of $\left(15 \mathrm{ng} \mathrm{mL}^{-1}\right)$ of VPS in methanol. (B) Excitation and (B') emission spectra of methanol. 


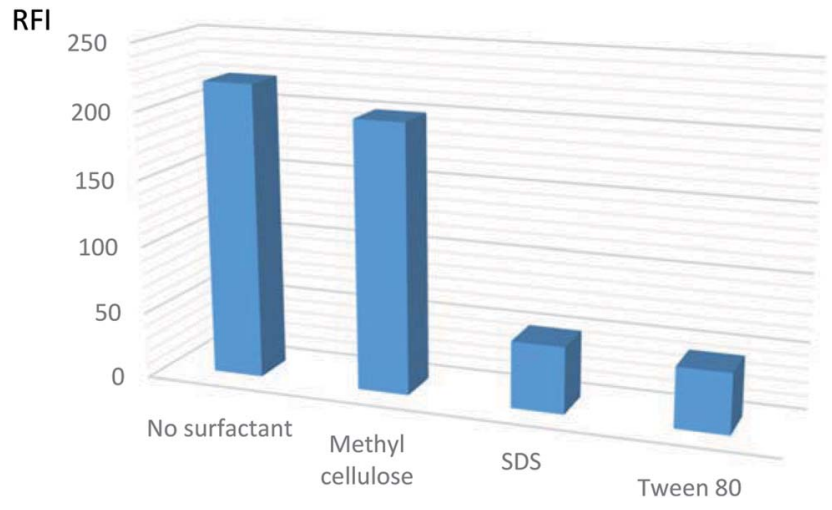

Fig. 3 Effect of different organized media on the relative fluorescent intensity (RFI) of VPS ( $5 \mathrm{ng} \mathrm{mL}^{-1}$ in methanol).

\subsection{Standard solutions}

Stock solution of concentration $100.0 \mu \mathrm{g} \mathrm{mL}^{-1}$ of VPS was prepared by dissolving $10 \mathrm{mg}$ of pure drug in $100 \mathrm{~mL}$ methanol with the aid of an ultrasonic bath. Working standard solution of $0.1 \mu \mathrm{g} \mathrm{mL}{ }^{-1}$ was prepared by appropriate dilution of the stock solutions with methanol. Solutions were properly stored in refrigerator to ensure their stability.

2.4.1. Calibration graph construction. Accurately measured volumes of the appropriate drug working standard solutions were delivered into a series of $10 \mathrm{~mL}$ volumetric flasks in order to prepare different solutions with concentrations in the range of $2.0-20.0 \mathrm{ng} \mathrm{mL}^{-1}$ of VPS, then the volume was completed with methanol. The fluorescence intensity was measured at $385 \mathrm{~nm} \& 400 \mathrm{~nm}$ after excitation at $295 \mathrm{~nm}$. The relative fluorescence intensity was plotted against the final concentration of VPS and the corresponding regression equations were computed.

2.4.2. Laboratory prepared mixture analysis. Stock solution of concentration $100.0 \mu \mathrm{g} \mathrm{mL}^{-1}$ of VPS and $400 \mu \mathrm{g} \mathrm{mL} \mathrm{m}^{-1}$ of SFV was prepared by dissolving the calculated amount of pure drugs in $100 \mathrm{~mL}$ methanol. Preparation of working standard solutions $\left(0.1 \mu \mathrm{g} \mathrm{mL} \mathrm{m}^{-1}\right.$ VPS and $0.4 \mu \mathrm{g} \mathrm{mL}^{-1} \mathrm{SFV}$ ) was done by diluting the stock solutions with methanol. The working standard solution was assessed by applying the procedure as described under "Calibration graph construction" and the corresponding concentration was calculated from the corresponding regression equation.

2.4.3. Procedures for tablets. Accurately weighed amount of the mixed contents of 10 powdered tablets equivalent to $10.0 \mathrm{mg}$ of VPS and $40.0 \mathrm{mg}$ of SFV was delivered into a $100 \mathrm{~mL}$ volumetric flask and around $30.0 \mathrm{~mL}$ methanol was added. The flask contents were sonicated for $30 \mathrm{~min}$, completed to the mark with the same solvent and filtered through cellulose acetate syringe filter. Further dilution with methanol was performed to obtain working standard solution to be estimated by applying the procedure cited under "Calibration graph construction" and the corresponding concentration was calculated from the corresponding regression equation.

\section{Results and discussion}

VPS was found to exhibit an intense native fluorescence in methanolic solution at 385 and $400 \mathrm{~nm}$ after excitation at $295 \mathrm{~nm}$ (Fig. 2). Hence, we aimed to utilize these emission bands to develop a new approach for accurate and selective VPS quantification in its bulk form as well as in its tablet.

\subsection{Factors affecting the fluorescence properties}

3.1.1. Effect of different organized media. The fluorescence properties of VPS in different organized media were investigated, using anionic surfactant (SDS), nonionic surfactant (Tween-80) and a macromolecule (methyl cellulose) where $1 \mathrm{~mL}$ of each surfactant $(1.0 \% \mathrm{w} / \mathrm{v})$ was added to a methanolic solution of the drug (final concentration $5 \mathrm{ng} \mathrm{mL}^{-1} \mathrm{VPS}$ ). It was found that SDS and Tween-80 caused decrease of relative fluorescence intensity (RFI) of VPS, while methyl cellulose results in no change in RFI when compared to the RFI without adding any surfactant (Fig. 3).

The results depicted that the use of surfactants caused no appreciable effect or may reduce the fluorescence intensity. Subsequently, the procedures were adapted without the use of any of the mentioned surfactants.

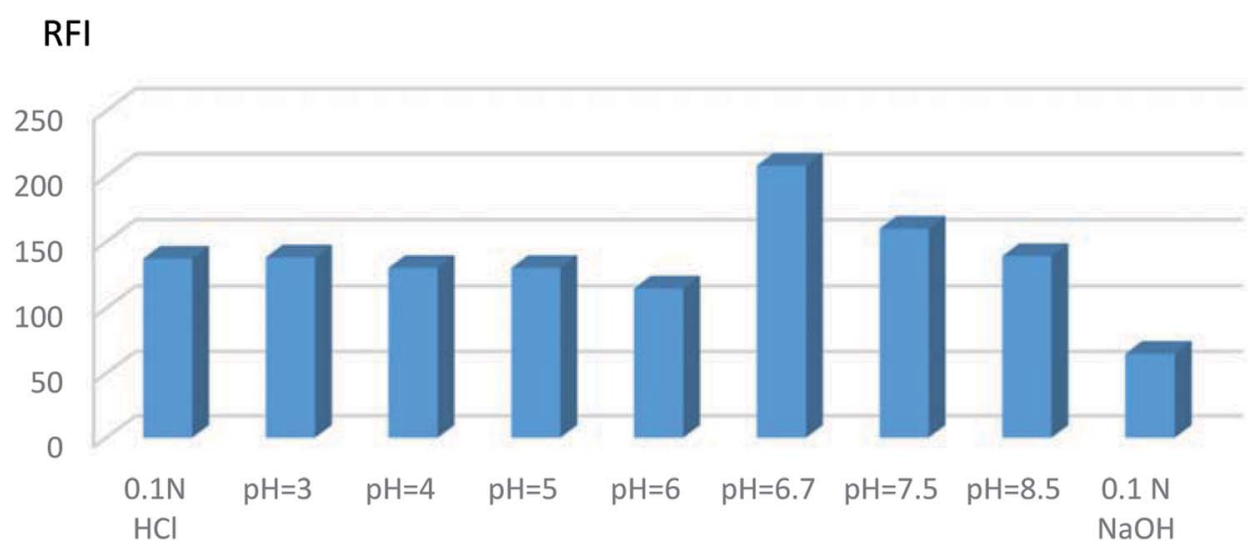

Fig. 4 Effect of different $\mathrm{pH}$ on the relative fluorescence intensity (RFI) of VPS ( $5 \mathrm{ng} \mathrm{mL}^{-1}$ in methanol). 


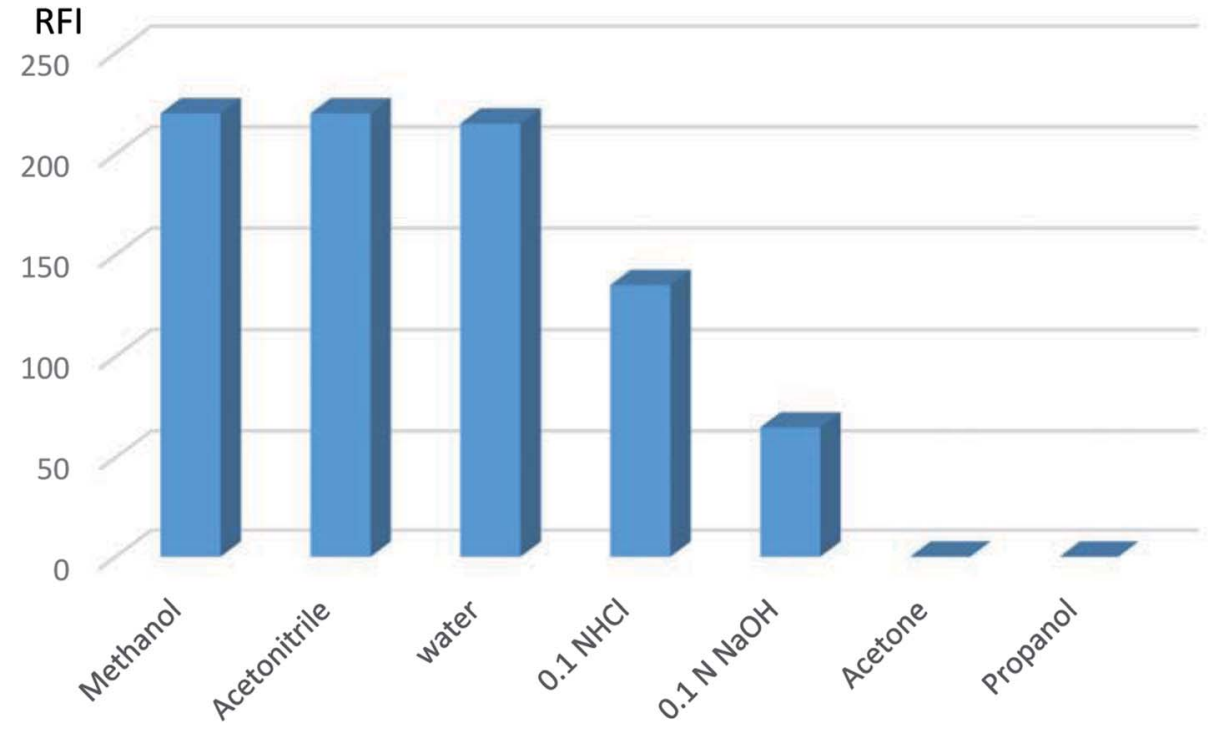

Fig. 5 Effect of different diluting solvents on the relative fluorescent intensity of VPS $\left(5 \mathrm{ng} \mathrm{mL}^{-1}\right)$.

Table 1 Analytical performance data for the determination of the studied drugs by the proposed method

\begin{tabular}{|c|c|c|}
\hline \multirow[b]{2}{*}{ Parameter } & \multicolumn{2}{|l|}{ Value } \\
\hline & At $385 \mathrm{~nm}$ & At $400 \mathrm{~nm}$ \\
\hline Linearity and range $\left(\mathrm{ng} \mathrm{mL}^{-1}\right)$ & $2.0-20.0$ & $2.0-20.0$ \\
\hline Correlation coefficient $(r)$ & 0.9999 & 0.9999 \\
\hline Slope & 40.406 & 39.980 \\
\hline Intercept & 28.976 & 14.805 \\
\hline$S_{y / x}$, S.D. of the residuals & 2.131 & 5.450 \\
\hline$S_{a}$, S.D. of the intercept & 1.792 & 4.584 \\
\hline$S_{b}$, S.D. of the slope & 0.146 & 0.373 \\
\hline S.D. & 0.60 & 0.89 \\
\hline$\% \mathrm{RSD}^{a}$ & 0.599 & 0.892 \\
\hline$\%$ error $^{b}$ & 0.267 & 0.399 \\
\hline $\operatorname{LOD}^{c}\left(\mathrm{ng} \mathrm{mL}^{-1}\right)$ & 0.146 & 0.378 \\
\hline $\mathrm{LOQ}^{d}\left(\mathrm{ng} \mathrm{mL}^{-1}\right)$ & 0.444 & 1.147 \\
\hline
\end{tabular}

${ }^{a}$ Percentage relative standard deviation. ${ }^{b}$ Percentage relative error.

${ }^{c}$ Limit of detection. ${ }^{d}$ Limit of quantitation.

3.1.2. $\mathbf{p H}$ effect. The $\mathrm{pH}$ impact on VPS fluorescence was studied using various types of buffers such as $0.2 \mathrm{~mol} \mathrm{~L}^{-1}$ acetate buffer (3.0-6.0) and $0.2 \mathrm{~mol} \mathrm{~L}^{-1}$ borate buffer (6.5-8.5), in addition to $0.1 \mathrm{~N} \mathrm{HCl}$ and $0.1 \mathrm{~N} \mathrm{NaOH}$. The buffer usage did not improve the RFI over the entire studied $\mathrm{pH}$ range. It was found that maximum RFI was obtained in methanolic solution without any buffer addition (Fig. 4).

3.1.3. Diluting solvent effect. The influence of various diluting solvents like, acetone, acetonitrile, $n$-propanol, methanol, water, $0.1 \mathrm{~N} \mathrm{HCl}$ and $0.1 \mathrm{~N} \mathrm{NaOH}$, on VPS fluorescence efficiency was studied. Complete fluorescence quenching was noticed upon using acetone or $n$-propanol. It was found that methanol, acetonitrile and water were the best solvents for dilution, as they showed the highest RFI with the lowest blank readings, however acetonitrile emission peak was blunt and the RFI in water was not quantitative (Fig. 5).
Hence, methanol was the diluting solvent of choice producing a more symmetric peak that increased quantitatively with the change in VPS concentration.

3.1.4. Time effect. The time effect on the RFI of VPS was studied. It was found that the fluorescence intensity remained constant for at least $1 \mathrm{~h}$.

3.1.5. Temperature effect. The temperature effect was studied in the range $40-100{ }^{\circ} \mathrm{C}$ in a thermostatically controlled water bath. The results showed that temperature elevation led to a decrease in RFI. This effect may be due to high probability of internal conversion at elevated temperatures. This may in turn lead to nonradiative deactivation of the excited singlet state. ${ }^{13}$ Consequently, all the experiments were carried out at room temperature.

\subsection{Method validation}

The method was validated in accordance to ICH recommendations. ${ }^{\mathbf{1 4}}$

3.2.1. Linearity. The linearity was checked by analyzing five VPS sets (standard calibration plots). The RFI against concentration plots were linear over a concentration range of 2.0-20.0 $\mathrm{ng} \mathrm{mL}^{-1}$ at both emission maxima (385 nm \& $\left.400 \mathrm{~nm}\right)$. The regression equations were computed to be:

$$
\begin{aligned}
& \mathrm{RFI}=28.976+40.406 C(r=0.9999) \text { at } 385 \mathrm{~nm} \\
& \mathrm{RFI}=14.805+39.980 C(r=0.9999) \text { at } 400 \mathrm{~nm}
\end{aligned}
$$

where: RFI is the relative fluorescence intensity, $C$ is the concentration of VPS in $\mathrm{ng} \mathrm{mL}^{-1}$ and $r$ is the correlation coefficient.

Statistical assessment ${ }^{15}$ of the results shows acceptable high correlation coefficient $(r)$ values and small values of standard deviation of residuals $\left(S_{y / x}\right)$. It also, reveals small values of standard deviation of intercept $\left(S_{a}\right)$, small values of the percentage relative standard deviation and the percentage relative error (Table 1). 
Table 2 Application of the proposed method for the analysis of the studied drug in its pure form

\begin{tabular}{|c|c|c|c|c|c|c|}
\hline \multirow[b]{3}{*}{ Studied drug } & \multicolumn{5}{|c|}{ Proposed method } & \multirow[t]{2}{*}{ Comparison method ${ }^{8}$} \\
\hline & \multirow[b]{2}{*}{$\begin{array}{l}\text { Conc. taken } \\
\left(\mathrm{ng} \mathrm{mL}^{-1}\right)\end{array}$} & \multicolumn{2}{|l|}{ At $385 \mathrm{~nm}$} & \multicolumn{2}{|l|}{ At $400 \mathrm{~nm}$} & \\
\hline & & $\begin{array}{l}\text { Conc. found } \\
\left(\mathrm{ng} \mathrm{mL}^{-1}\right)\end{array}$ & $\%$ found & $\begin{array}{l}\text { Conc. found } \\
\left(\mathrm{ng} \mathrm{mL}^{-1}\right)\end{array}$ & $\%$ found & $\%$ found \\
\hline \multirow[t]{5}{*}{ At $385 \mathrm{~nm}$} & 2.0 & 1.9805 & 99.03 & 2.006 & 100.30 & 101.12 \\
\hline & 5.0 & 4.9751 & 99.50 & 5.007 & 100.15 & 102.45 \\
\hline & 10.0 & 10.0486 & 100.49 & 9.885 & 98.85 & 99.78 \\
\hline & 15.0 & 15.0478 & 100.32 & 15.187 & 101.25 & 101.77 \\
\hline & 20.0 & 19.9480 & 99.74 & 19.915 & 99.57 & 99.14 \\
\hline$X \pm \mathrm{SD}$ & $99.82 \pm 0.60$ & \multicolumn{4}{|c|}{$100.02 \pm 0.890$} & \multirow[t]{3}{*}{$100.85 \pm 1.37$} \\
\hline$t$-test & $1.55(2.31)^{a}$ & & $1.13(2$ & & & \\
\hline$F$-test & $5.27(6.39)^{a}$ & & $2.37(6$ & & & \\
\hline
\end{tabular}

${ }^{a}$ Figures between parentheses are the tabulated $t$ and $F$ values at $P=0.05 .{ }^{15}$ Each result is the average of three separate determinations.

3.2.2. Detection and quantification limits. Limit of quantitation (LOQ) was identified as the lowest concentration that can be accurately determined. The limit of detection (LOD) was identified as the lowest detectable concentration of the analyte. ${ }^{\mathbf{1 4}}$ The results are abridged in Table 1.

3.2.3. Accuracy and precision. Statistical comparison ${ }^{15}$ between the results obtained by adopting the proposed method and those obtained by the reference method ${ }^{8}$ using Student's $t$ test and variance ratio $F$-test revealed no significant differences between the two methods regarding accuracy and precision (Table 2).

The intraday precision was assessed by determining three different VPS concentrations on the same day. On the other hand, interday precision was determined by quantifying three different concentrations over three consecutive days (Table 3).

Acceptable repeatability and intermediate precision of the cited method were assured by the very small values of relative standard deviations.

3.2.4. Selectivity. It was studied by checking the incidence of any interference coming from the common excipients or the co-formulated drug (SFV). It was clear that these compounds did not interfere with the results of the proposed method which ensure the high selectivity of the proposed method for VPS.

\subsection{Analysis of VPS and SFV in a laboratory prepared mixture of their pharmaceutical ratio}

The cited procedure was applied to the determination of VPS in a laboratory prepared mixture with SFV at their pharmaceutical ratio $(1: 4)$. The results obtained are summarized in Table 4 . The results were in good agreement with those obtained using the reference method. ${ }^{8}$

\subsection{Application to dosage form}

The cited method was applied to determine VPS in its commercially available tablet form (Table 5). The results were in good agreement with those achieved using the reference method. ${ }^{8}$

Table 3 Precision data for the determination of the studied drugs by the proposed method

\begin{tabular}{|c|c|c|c|c|c|c|c|}
\hline \multirow[b]{3}{*}{ Parameters } & & \multicolumn{3}{|l|}{ At $385 \mathrm{~nm}$} & \multicolumn{3}{|l|}{ At $400 \mathrm{~nm}$} \\
\hline & & \multicolumn{3}{|c|}{ Concentration $\left(\mathrm{ng} \mathrm{mL}^{-1}\right)$} & \multicolumn{3}{|c|}{ Concentration $\left(\mathrm{ng} \mathrm{mL}^{-1}\right)$} \\
\hline & & 5.0 & 10.0 & 15.0 & 5.0 & 10.0 & 15.0 \\
\hline \multirow[t]{6}{*}{ Intraday } & $\%$ found & 99.50 & 100.49 & 100.32 & 100.15 & 98.85 & 101.25 \\
\hline & & 100.11 & 98.88 & 101.13 & 99.74 & 99.45 & 100.84 \\
\hline & & 101.22 & 98.45 & 98.94 & 100.98 & 98.73 & 99.32 \\
\hline & $(\bar{x}) \pm$ S.D. & $100.28 \pm 0.87$ & $99.27 \pm 1.08$ & $1001.3 \pm 1.11$ & $100.29 \pm 0.63$ & $99.01 \pm 0.39$ & $100.47 \pm 1.02$ \\
\hline & $\%$ RSD & 0.87 & 1.08 & 1.11 & 0.63 & 0.39 & 1.01 \\
\hline & $\%$ error & 0.50 & 0.63 & 0.64 & 0.36 & 0.23 & 0.58 \\
\hline \multirow[t]{6}{*}{ Inter-day } & $\%$ found & 99.50 & 100.49 & 100.32 & 100.15 & 98.85 & 101.25 \\
\hline & & 98.76 & 99.21 & 99.50 & 98.86 & 100.43 & 100.55 \\
\hline & & 100.37 & 98.65 & 100.68 & 99.02 & 98.15 & 99.68 \\
\hline & $(\bar{x}) \pm$ S.D. & $99.54 \pm 0.81$ & $99.54 \pm 0.94$ & $100.17 \pm 0.61$ & $99.34 \pm 0.70$ & $99.14 \pm 1.17$ & $100.49 \pm 0.79$ \\
\hline & $\%$ RSD & 0.81 & 0.95 & 0.60 & 0.71 & 1.18 & 0.78 \\
\hline & $\%$ error & 0.47 & 0.55 & 0.35 & 0.41 & 0.68 & 0.45 \\
\hline
\end{tabular}

N. B. each result is the average of three separate determinations. 
Table 4 Assay results for the determination of the studied drug in a laboratory prepared mixture with SPV at their pharmaceutical ratio

\begin{tabular}{|c|c|c|c|c|c|c|}
\hline Combination & \multicolumn{5}{|c|}{ Proposed method } & Comparison method $^{8}$ \\
\hline SFV/VPS mixture $4 / 1$ & 5.0 & 5.018 & 100.35 & 5.035 & 100.69 & 101.45 \\
\hline Mean & & & 99.25 & & 100.58 & 100.35 \\
\hline \pm S.D. & & & 1.11 & & 1.14 & 1.17 \\
\hline$t$-Test & & & $1.18(2.78)^{a}$ & & $-0.25(2.78)^{a}$ & \\
\hline$F$-Test & & & $1.11(19.0)^{a}$ & & $1.05(19.0)^{a}$ & \\
\hline
\end{tabular}

${ }^{a} \mathrm{~N}$. B. each result is the average of three separate determinations. The figures between parentheses are the tabulated $t$ and $F$ values at $P=0.05 .{ }^{15}$

Table 5 Assay results for the determination of the studied drug in its co-formulated tablet with SPV

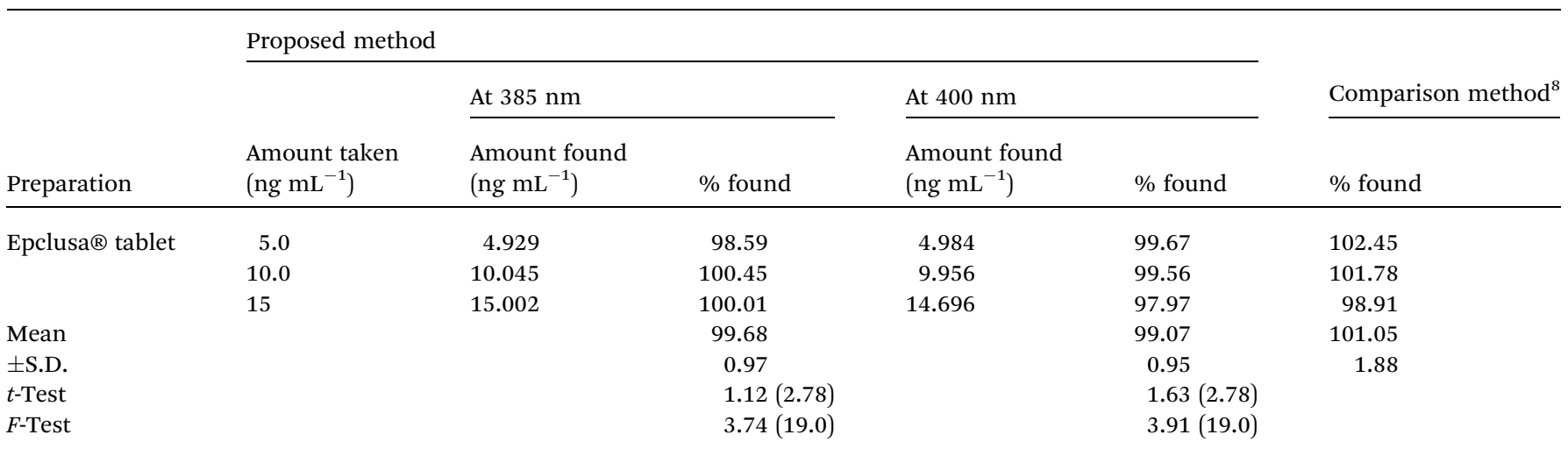

The figures between parentheses are the tabulated $t$ and $F$ values at $P=0.05 .^{15}$

\section{Conclusion}

A new simple rapid and highly sensitive spectrofluorimetric method was clarified for the selective quantification of VPS in presence of its co-formulated drug (SFV) either in bulk or dosage forms. The cited method is rapid, economic and does not require the elaborate treatment associated with chromatographic methods or previously reported spectrofluorimetric method. In addition, the proposed method shows high sensitivity, with no need for derivatization procedures. This method can be applied for the sensitive and selective determination of VPS in the routine quality control work.

\section{Conflicts of interest}

The authors declare no conflict of interest.

\section{Acknowledgements}

This project was supported by the Deanship of Scientific Research at Prince Sattam Bin Abdulaziz University under the research project \# 2017/03/7249.

\section{References}

1 H. S. Te and D. M. Jensen, Epidemiology of hepatitis B and C viruses: a global overview, Clin. Liver Dis., 2010, 14, 1-21.

2 PubChem (2018), https://pubchem.ncbi.nlm.nih.gov/ compound/Velpatasvir\#section=Top, accessed, 12 February 2018.

3 Wikipedia (2018), https://en.wikipedia.org/wiki/Sofosbuvir, accessed, 12 February 2018.

4 Drugs.com (2018), https://www.drugs.com/history/ epclusa.html, accessed, 12 February 2018.

5 S. A. Abdel-Gawad, Simple chromatographic and spectrophotometric determination of sofosbuvir in pure and tablet forms, Eur. J. Chem., 2016, 7, 375-379.

6 M. Miraghaei, B. Mohammadi, A. Babaei, S. Keshavarz and G. Bahrami, Development and validation of a new HPLCDAD method for quantification of sofosbuvir in human serum and its comparison with LC-MS/MS technique: application to a bioequivalence study, J. Chromatogr. B: Anal. Technol. Biomed. Life Sci., 2017, 1063, 118-122.

7 M. Nebsen and E. S. Elzanfaly, Stability-Indicating method and LC-MS-MS characterization of forced degradation 
products of sofosbuvir, J. Chromatogr. Sci., 2016, 54, 16311640.

8 J. Uppalapati and U. DrParimi, Analytical method development and validation for the simultaneous estimation of sofosbuvir and velpatasvir drug product by RP-HPLC method, Indo Am. J. Pharm. Res., 2017, 7, 401-409.

9 J. Bandla and S. Ganapaty, Stability indicating RP-HPLC method development and validation for the simultaneous determination of Sofosbuvir and Velpatasvir in tablet dosage forms, Indian J. Pharm. Biol. Res., 2017, 5, 10-16.

10 N. Sarath and J. V. L. N. Seshagiri Rao, A stability indicating RP-HPLC method for simultaneous estimation of velpatasvir and sofosbuvir in combined tablet dosage forms, World J. Pharm. Pharm. Sci., 2017, 6, 1596-1611.

11 G. K. Swamy, K. Pranay, M. Rajkumar and D. Sudheer Kumar, Novel stability indicating RP-HPLC method simultaneous determination of sofosbuvir and velpatasvir in bulk and combined tablet dosage forms, Asian J. Res. Biol. Pharm. Sci., 2017, 5, 143-151.
12 M. E. Mohamed, R. H. A. Hassan, A. M. Adel and A. Ramadan, Enhanced dispersive solid phase extraction assisted by cloud point strategy prior to fluorometric determination of anti-hepatitis $\mathrm{C}$ drug velpatasvir in pharmaceutical tablets and body fluids, RSC Adv., 2018, 8, 13292-13300, https://pubs.rsc.org/en/content/ articlelanding/2018/ra/c7ra13719b\#!divAbstract.

13 G. G. Guilbault, Fluorescence, theory, instrumentation and practice, Marcel Dekker, Inc., New York, USA, 1967.

$14 \mathrm{ICH}$ Harmonized Tripartite Guidelines, validation of analytical procedures: Text and Methodology, Q2(R1), current Step 4 Version, arent Guidelines on Methodology Dated November 6 1996, Incorporated in November 2005, through (https://www.ich.org/LOB/media/MEDIA417.pdf), (accessed February 9, 2018).

15 J. N. Miller, and J. C. Miller, Statistics and chemometrics for analytical chemistry, Pearson Education Limited, Harlow, 2005. 